\section{Novel heterogeneous stiffness for dynamic compression reconstruction}

\section{Rong Liu}

Institute of Textiles and Clothing, The Hong Kong Polytechnic University, Hum Hom, Kowloon, Hong Kong SAR

\begin{abstract}
Compression therapy is the recommended non-pharmaceutical choice for edema and ulcers treatment through delivering static or dynamic pressure dosages to the affected legs. The traditional compression modalities were prone to generate peak or uneven cutaneous pressure around anatomic geometries, leading to ischemia or deficient pressure delivery as well as discomfort or high non-compliance in clinical practice. The aim of this study was to
\end{abstract}

reconstruct compression exertion through novel designed heterogeneous threedimensional knitting structures and stiffness control to avoid sustained peak pressure but enhance muscular pumping action. The new heterogeneous structures integrate yielding and non-yielding elastic design via advanced tension controlled weft-knitting technologies to carter for anatomic morphologies and pressure requirements of the target users. The study indicated that the hybrid ratios of elasticity and their segmental proportions significantly influence cutaneous pressure profile. The new heterogeneous structures can generate hybrid DSI in compression shells with customized figurations. The designed heterogeneous stiffness reconstructed compression around the lower limbs with reduction of cutaneous pressure at anterior tibia bone crest by $2.0 \%-9.6 \%(\mathrm{P}<0.05)$ while increased those at posterior gastrocnemius regions by 9.3 $34.6 \%(\mathrm{P}<0.05)$, resulting in more rationally pressure profiles around lower limb but maintaining degressive gradient from distal
Correspondence: Rong Liu, Institute of Textiles and Clothing, The Hong Kong Polytechnic University, Hum Hom, Kowloon, Hong Kong SAR.

E-mail: rong.liu@polyu.edu.hk

Conference presentation: International Compression Club (ICC) Meeting, Paris, 2017.

This work is licensed under a Creative Commons Attribution 4.0 License (by-nc 4.0).

(C) Copyright R. Liu, 2018

Licensee PAGEPress, Italy

Veins and Lymphatics 2018; 7:7627

doi:10.4081/vl.2018.7627

to proximal lower limb. The novel compression structures also present positive wearing feedback in our on-going clinical wear trials, which contribute to promote pressure function and user's compliance in practice. 